\title{
Exploration the Role of a Clinical Supervisor to Improve the Professional Skills of Medical Students in IRAN: A Content Analyze Study
}

Mohammad Hasan Keshavarzi

Shiraz University of Medical Sciences

Salimeh khalili Azandehi

Valiasr Regional Hospital

Hamidreza Koohestani

Saveh University of Medical Sciences

Hamid Reza Baradaran Attar Moghadam

Iran University of Medical Sciences

Ali Asghar Ghorbani ( $\nabla$ a_ghorbani85@yahoo.com )

Mazandaran University of Medical Sciences

Ali Asghar Hayat

Shiraz University of Medical Sciences

\section{Research Article}

Keywords: Clinical supervisor, professional skills, responsibilities \& characteristics, medical students

Posted Date: August 26th, 2021

DOl: https://doi.org/10.21203/rs.3.rs-753796/v1

License: (9) (i) This work is licensed under a Creative Commons Attribution 4.0 International License. Read Full License 


\section{Abstract}

\section{Background}

Clinical supervision is a supporter for learners and paves the way for effective and efficient learning in clinical settings. This study aimed to explain the responsibilities of clinical supervisors in clinical education wards to improve the professional skills of medical students.

\section{Methods:}

In this qualitative study, we used the conventional content analysis approach. The sample consisted of 16 faculty members of Iranian universities of medical sciences and medical graduates. Purposeful sampling and semi-structured interviews were used to collect data. The Granheim and Landman method (2004) was used to analyze the data.

\section{Results:}

From the analysis of interviews, 2 themes, 8 categories, and 18 subcategories were obtained. "Clinical supervisor responsibilities" as a theme includes the categories: "Creating motivation in learner", "Learner's need recognition", "Performance evaluation", "Creating learning opportunities", and "Professional ethics education". And, the sub-categories were: "Creating a supportive atmosphere", "Task assignment" ,"Understanding training needs", "Understanding individual needs", "Periodic evaluation”, "Proper feedback', "Reduce work stress", "Learner engagement', "Learning Facilitation”, "Attention to the patient's treatment", and "Ethical observance in relation to patients".

As the second theme "Clinical supervisor characteristics" included the categories of: "Scientific competence", "Leading role", and "Ethical model". Their sub-categories are clustered as: "Knowledge of educational concepts", "Mastery of professional concepts", "Effective communication skills", "Understanding managerial concepts", "High resilience", "Career commitment ", and " social commitment $"$

\section{Conclusions}

The clinical supervisor will improve the professional skills of medical students, which will improve the quality of services provided, train efficient graduates, and provide a safe and relaxing environment that leads to patient satisfaction.

\section{Introduction}

Medicine is perceived as one of the sacred and praiseworthy professions in every society. In all countries, comprehensive and appropriate in-service education for the empowerment and efficiency of healthcare workers has been on the top agenda of educational planners (1). 
One of the characteristics of medical education is the need to learn practical and communication skills along with cognitive and theoretical domains (2). Clinical education is a dynamic process in which students gradually gain experience by attending the patient's bedside and prepare their minds to solve the patient's problems by using the experiences and logical arguments gained (3-5). Clinical education is one of the critical stages of medical education that plays a major role in shaping the professional abilities of learners and is an essential part of physician training as responsible for maintaining and promoting public health (6).

Providing the highest quality of clinical education to medical students is crucial for the delivery and care of public health (7). The inability of medical students to acquire clinical skills could be attributable to the weak and insufficient educational capacity in the country's universities (6). Therefore, clinical education plays a pivotal role in the formation of professional identity (8).

The first investigations into the idea of clinical supervision were carried by Gold Hummer in the 1960s (9) which focused on the data collection process during supervisions (10). In 1973, Cogan developed and supported the concept of clinical supervision, noting the importance of professional interactions between stakeholders to contribute to the professional advancement of clinical educators. He also introduced clinical supervision stages that focused on planning, observation, and feedback (11). Supervision includes ensuring inclusive patient safety during clinical care, providing informal feedback, and providing critical input to primary education and continuing education programs as well as monitoring and progress(12).

Ensuring inclusive patient safety during clinical practices is an essential element of clinical supervision (13). Effective supervision is an activity that creates growth and authority in the supervised group, facilitates the work of supervision and supports both the client and the supervisor (14). Tracing the quality of educational supervision in Tehran hospitals, Razmjoo et al. claimed that there is no effective clinical supervision in hospitals for residents (15).

Despite the benefits of a clinical supervision program; however, this position is not yet well designed in Iranian teaching hospitals. Students would be confronted with new environments that they do not have enough familiarity and experience with, and countless questions would arise in their minds. Since the medical students will be present in the clinical environment following the completion of basic sciences and pathophysiology courses and will gain insights on how to interact with the patient and family and various professional skills, the position of clinical supervisor will have a great impact on knowledge transfer to students.

Therefore, this study has tended to explain the duties and characteristics of clinical supervisors in clinical settings to strengthen the professional skills of medical students in Iranian universities of medical sciences.

\section{Materials And Methods}


In this research, a qualitative approach and contractual content analysis, the purpose of which is to describe a phenomenon, was used. Qualitative research was incorporated to achieve the inner world of participants and to discover the meanings formed in a cultural context (16). Content analysis is a suitable way to obtain valid results from textual data and to create new knowledge, insights, and facts and provides the direction that all organizational efforts will follow (17).

\section{Inclusion and exclusion criteria}

The initial samples were consisting of faculty members of medical universities who had a history of teaching responsibilities in the clinical environment and teaching hospitals. Also, the criteria for the selection of students were those about to graduate or have already graduated in medicine. Exclusion criteria were the participants' unwillingness to continue cooperation.

\section{Data Collection}

Semi-structured interviews were used to collect information. To further the coordination with the participants, the objectives of the research were explained before the interview. A written informed consent form was given to the interview participants. The interviewees explicitly agreed to record the interview. The interviews were conducted on an individual basis. During the interview, a general question was asked first and then, as the interview progressed, the questions were controlled in the direction of the research goal. Questions asked in the interview were:

"Express your understanding of educational supervision in a clinical setting?", " What qualities do you think a clinical supervisor should have?", "How can you be a good clinical supervisor?", "In your opinion what are the roles and responsibilities of a clinical supervisor in a clinical setting with the attendance of students?". Also, a series of in-depth questions were asked: "Can you explain more?" Talk about "," "you mentioned ...., what you meant?".

Also, the students were asked questions like: "Describe your experience from the clinical course you went through", "Describe your experience with the activities and roles of a clinical supervisor in hospital wards?", "Based on your experience with the clinical environment, what characteristics can the clinical supervisor have to improve the quality of learning?". Each interview lasted 35 to 45 minutes and was conducted by the first author.

Participants were selected by the purposive sampling method from among the informants who provided the most data about the study subject. The interview site was either hospital or university environment decided upon by close interaction of the researcher and participants. A total of 16 people participated in the interviews (see Table 1). 
Demographic characteristics of the interviewees

\begin{tabular}{|cllll|}
\hline P & Field of Study & $\begin{array}{l}\text { Academic } \\
\text { Ranking }\end{array}$ & Gender & CME \\
\hline 1 & General Surgery & Assit. Professor & Male & MSc in Medical Education \\
\hline 2 & Anesthesiologist & Assoc. Professor & Male & CME credit in medical education \\
\hline 3 & Cardiologist & Assit. Professor & Male & MSc in Medical Education \\
\hline 4 & Restorative Medicine & Assit. Professor & Male & CME credit in medical education \\
\hline 5 & Internist & Assoc. Professor & Male & MSc in Medical Education \\
\hline 6 & Emergency Medicine & Assit. Professor & Male & MSc in Medical Education \\
\hline 7 & Anesthesiologist & Assoc. Professor & Male & CME credit in medical education \\
\hline 8 & General Surgery & Assoc. Professor & Male & MSc in Medical Education \\
\hline 9 & ENT specialist & Assit. Professor & Male & CME credit in medical education \\
\hline 10 & $\begin{array}{l}\text { Bone and joint } \\
\text { specialist }\end{array}$ & Assit. Professor & Male & MSc in Medical Education \\
\hline 11 & Social medicine & Assoc. Professor & Male & MSc in Medical Education \\
\hline 12 & Medical Student & Medical Graduate & Male & CME credit in medical education \\
\hline 13 & Medical Student & Medical Graduate & Female & MSc student in Medical Education \\
\hline 14 & Medical Resident & Medical Graduate & Male & CME credit in medical education \\
\hline 15 & Medical Resident & Medical Graduate & Male & $\begin{array}{l}\text { MSc student in Medical } \\
\text { Education }\end{array}$ \\
\hline 16 & Medical Resident & Medical Graduate & Female & CME credit in medical education \\
\hline
\end{tabular}

\section{Data analysis method}

Granheim and Landman (2004) approach was used in data analysis(18). In this study, immediately after each interview, the audio file was carefully transcribed by the first author. Manuscripts and notes were added to the written text. The content was then reviewed several times by the authors to find further relations to the data, to attain data immersion, and to gain a better understanding of what the interviewees were saying .

The meaning units were then identified and coded. The codes were merged based on similarity and were clustered into several sub-categories. Next, the sub-categories formed main categories based on similarities and differences. Attempts were made to have the greatest homogeneity within the categories. Incorporating the categories, the themes or abstract ideas emerged. 


\section{Data rigidity}

We employed the four key criteria developed by Lincoln and Guba, including credibility, transferability, dependability, and confirmability (19).

Regarding credibility, the researcher's continuous presence in the field provided the researcher with a better understanding of the phenomenon. Allocating enough time to collect and analyze data helped the authors gain deep insight into the data.

For the sake of transferability, interviews, coding, and analysis were recorded and reported in detail in all the research processes.

The dependability was established using techniques such as using the opinions of the research team and double-checking of the codes to determine that there is an agreement between the extracted categories and sub-categories.

Regarding confirmability, several interviews, extracted codes and categories were reviewed by two faculty members familiar with data analysis of qualitative research.

\section{Ethical considerations}

In this study, after coordination with the relevant authorities and obtaining the consent and approval of the participants, the interview was conducted. Confidentiality was also observed.

\section{Findings}

Out of 16 participants, 12 were faculty members and the remaining were the final-year medical students and residents. From the analysis of interviews, 2 themes, 8 categories and 18 subcategories were obtained after coding and comparing the codes with each other and based on similarities and differences (see Table 2).

\section{Table 2}

Sub-category, Category, Themes 


\begin{tabular}{|c|c|c|}
\hline Sub-category & Category & Themes \\
\hline Creating a supportive atmosphere & \multirow{2}{*}{$\begin{array}{l}\text { Creating motivation in } \\
\text { learner }\end{array}$} & \multirow{11}{*}{$\begin{array}{l}\text { Clinical supervisor } \\
\text { responsibilities }\end{array}$} \\
\hline Task assignment & & \\
\hline Understanding training needs & \multirow[t]{2}{*}{ Learner's need recognition } & \\
\hline Understanding individual needs & & \\
\hline Periodic evaluation & \multirow[t]{2}{*}{ Performance evaluation } & \\
\hline Proper feedback & & \\
\hline Reduce work stress & \multirow{3}{*}{$\begin{array}{l}\text { Creating learning } \\
\text { opportunities }\end{array}$} & \\
\hline Learning Facilitation & & \\
\hline Learner engagement & & \\
\hline Attention to the patient's treatment & \multirow{2}{*}{$\begin{array}{l}\text { Professional ethics } \\
\text { education }\end{array}$} & \\
\hline $\begin{array}{l}\text { Ethical observance in relation to } \\
\text { patients }\end{array}$ & & \\
\hline Knowledge of educational concepts & \multirow[t]{2}{*}{ Scientific competence } & \multirow{7}{*}{$\begin{array}{l}\text { Clinical supervisor } \\
\text { characteristics }\end{array}$} \\
\hline Mastery of professional concepts & & \\
\hline Effective communication skills & \multirow[t]{3}{*}{ Leading role } & \\
\hline Understanding managerial concepts & & \\
\hline High resilience & & \\
\hline Career commitment & \multirow[t]{2}{*}{ Ethical mode } & \\
\hline social commitment & & \\
\hline
\end{tabular}

\section{Theme 1: Clinical Supervisor's Responsibilities}

The themes of Clinical Supervisor's Responsibilities include 5 main categories of "create the motivation", " understanding learner's needs ", "performance appraisal", "create the learning opportunity" and "professional ethics training".

\section{Creating motivation in the learner}

It refers to the reinforcing factor and the desire of learners to learn and provide more service. Its subcategories are "creating a supportive atmosphere " and "task assignment". 


\subsection{Creating a supportive atmosphere}

It refers to the creation of psychological and even legal support in the clinical environment, part of which is the responsibility of the supervisor. "The treatment environment is a stressful and anxious environment for both the patient and the therapist. This is where a supporter, an encourager and a word of hope can keep your engine running, or either," said one participant. "If a cold word or a certain behavior stops your engine, this is where the presence of a supporter is felt in this situation," he continued ( $P-7)$.

\subsection{Task assignment}

In the clinical setting, students' duties and roles should be clearly defined; doing so they perform their duties properly like other medical staff. "If I know what I have to do in a clinical setting I feel good, unlike the situation where I am unaware about what I am expected to do, from history-taking and physical examination to filling a medical history form and many other confusing things, "pinpointed one participant. (P-15)

\section{Learner's need recognition}

The clinical supervisor has to recognize the educational needs of the learners. Its sub-categories are "Understanding educational needs", "Understanding individual needs"

\subsection{Understanding training needs}

The clinical supervisor should be aware of the needs of the various levels of students present in the clinical setting, including stagers, students and interns, and residents. "When I was an intern, some of the cases we visited were very complicated and incomprehensible to our level of medical knowledge, I had a bad feeling there. We did not know if we had difficulty in learning or not, they are certain "fellow and residents cases, and this boundary was not clear to us and there was no one available to answer the questions." said another participant ( $P-16)$.

\subsection{Understanding individual needs}

The clinical supervisor should be aware of the different characteristics of learners and their age and gender requirements. "Although I had a lot of energy and ideas, I swallowed my idea for fear of being humiliated.... nobody seemed to understand us. Everyone was used to the usual routine "asserted one participant (P 14). Some professors only had a good relationship with a certain gender group and did not pay attention to us, they did not even understand our situation", said another participant (P 16). 


\section{Performance evaluation}

It includes comprehensive monitoring and evaluation during the training course in the clinical environment to ensure students' attainment of educational goals (i.e. Knowledge, attitude and skills). Its subcategories are "periodic evaluation" and " proper feedback".

\subsection{Periodic evaluation}

It refers to conducting assessments during the study and in each of the clinical wards and educational environments. One participant says, "We have now designed software to record the attendance and activities daily. The issue of student evaluation is very important. And not that at the end of the semester the instructor, who does not even remember the names of the students, give a grade carelessly and on no basis", said one faculty member (P5).

\subsection{Proper feedback}

Providing feedback to address deficiencies and shortcomings is valuable. However, this feedback should be provided thoughtfully and appropriately to the learner. One participant said, "I have been receiving feedback from students every three weeks since I became in charge of supervising the students in the ward. I ask them, what were the good wards and the bad ones? Write the positive and negative points. When 10 out of 60 students write that this ward does not have ta good training, it means that there is something wrong with that particular ward. I get the feedback, I talk to the Head and the faculty of that ward, and I retry again two weeks later".(P:8)

\section{Creating learning opportunities}

The educational supervisor can promote educational activities by using measures such as providing educational equipment, creating a healthy and fear-free learning atmosphere. Its subcategories are "reduce work stress ", "learner engagement" and "learning facilitation."

\subsection{Reduce work stress}

Creating a calm atmosphere is the basis for effective learning and teaching. "During this time, I saw a lot of students who are restless, especially during the busy period, due to the heavy workload, stressful work environment, insomnia and many other things. Sometimes, I talk to them about my old experiences and big problems I had before and that they are all over now... they cheer up and feel energetic," said one participant (P: 2). 


\subsection{Learner engagement}

Giving responsibility and involving participants in group learning activities (e.g. rounds, journal clubs, etc.) is part of engaging students. "Some instructors do not put students in a position of scientific evaluation at all. The round is one-sided. They do not ask the student for any clinical judgment,"said one participant (P: 14).

\subsection{Learning Facilitation}

It refers to the provision of educational materials and equipment to facilitate educational activities. "Many of the hospitals we worked there had poor teaching facilities; they didn't have a good library to study or to find the references we needed. There were old computers, we had to bring our own, However, in the hospital environment, and the educational supervisor can provide the students with facilities like an amphitheater, conference room to hold a journal club, infection control and advanced resuscitation sessions and many other things that can be useful for students. " asserted one participant(P:5).

\section{Professional ethics education}

"Professional ethics education" deals with another responsibility of the clinical supervisor that is related to the patient. In addition to the student, the clinical supervisor must pay sufficient attention to the patient. Its sub-categories are "Attention to patient treatment "," Ethical observance about the patient".

\subsection{Attention to patient's treatment}

It refers to the clinical supervisor's sense of responsibility and attention to the patient's treatment process. "The patient who comes to the hospital with a thousand hopes is terrified and emotionally involved. The educational supervisor should also pay attention to this issue. On the other hand, care should be taken not to sacrifice education for treatment," pinpointed one participant. (P: 9)

\subsection{Ethical Observance in relation to patients}

It refers to the rules and regulations regarding the observance of ethical issues and the human dignity of the patient in the clinical environment. "Rarely, however, there were professors with a weak perception of ethics. They shouted at the patients. They insulted them. They did not follow the charter of the patient's rights. The patient did not dare to squawk either because they were unaware of their rights....... well..... Part of this of course is due to the high workloads and a large number of patients and the multiple responsibilities of the professors which it made it difficult to work in a teaching hospital. It was here that a need for a clinical supervisor was felt."(P: 12) 


\section{Theme 2: Personal characteristics of clinical observer}

The second theme refers to the characteristics of a clinical observer. This theme has three main categories: "scientific competence", "guidance" and "ethical model."

\section{Scientific competence}

"Scientific competence" refers to the personal competence and knowledge of a clinical supervisor in the field of professional and specialized issues. Its subcategories are "knowledge of educational concepts" and "mastery of professional concepts."

\subsection{Knowledge of educational concepts}

It refers to the clinical observer's familiarity with related concepts in teaching and learning. "As a clinical professor, I have to be a teacher other than a specialized instructor. I should love education and have a concern about my field of education. I have to take a medical education course and increase my knowledge of training, needs assessment, evaluation and teaching methods, "said one participant.(P:3).

\subsection{Mastery of professional concepts}

It refers to the knowledge and skills of the clinical supervisor in the specialized and professional field of medicine and clinical wards. In this regard one of the participants said: "The person who claims to teach the student must have even more knowledge in that field than other instructors ... The student must feel that the teacher is capable, has mastery, this way he/she can trust the teacher because he believes the instructor has sufficient expertise in the field".(P:1)

\section{Leading role}

"leading role" is one of the traits of the clinical supervisor who guides learners in the process of teaching in a clinical environment. Of course, student leadership is achieved through good interaction. Its subcategories are "effective communication skills", "understanding managerial concepts", "high resilience."

\subsection{Effective communication skills}

This sub-category is related to having the appropriate communication skills between the supervisor and the learner. "There are many times when I wish I had more time to talk to the teacher, but the connection between us is cut off and that connection is not established between the teacher and the student, 
especially during the externship and internship.", said one participant. "their instructors are so busy and have so many students that they won't always be available so that when it comes to you to say something either the professor is paged or the phone rings and so on", he continued (P:14)

\subsection{Understanding managerial concepts}

Awareness of the basic concepts of management, including planning, organizing and monitoring is an integral part of working in organizational environments. "Everywhere in the world, it has been proven that when you take a job, despite your expertise, you have to know something about management science. Someone who is a clinical supervisor must know about management factors and must have experienced how to interact and do conflict management," said one participant.",(P:8)

\subsection{High resilience}

This sub-category addresses the resilience of the clinical supervisor in the face of shortcomings, deficiencies and criticisms in the educational environment. "During this time, I witnessed a professor clashing with a student. In many places, complaints were lodged inside the university or even in the judiciary. I did not expect that student, but I was expecting more sobriety and better patience from the professor," said one participant(P:6).

\section{Ethical model}

The clinical supervisor in the clinical setting should be a role model for other students. Its sub-categories are "career commitment ", "social commitment ".

\subsection{Career Commitment}

It refers to being a moral role model and a good reputation. One of the participants said, "The first day we entered the ward, the teacher came earlier than everyone else. All the students gathered around the instructor. He was a stylish professor. After a short introduction, the instructor said... listen .... This is a holy place, the patient's body is holy. That he/she allows us to examine his body and learn something, he has been very kind to us. Don't say it smells bad! ... doric. I did not expect him to say such things (P: 5).

\subsection{Social Commitment}

It refers to the clinical supervisor's sense of responsibility to the organization, the community, the patient and the students." Our teacher used to bring us together every week and said that God has given us the 
opportunity to serve human beings. Seize this opportunity. Do not miss a moment of serving the people", said one participant. (P: 14)

\section{Discussion}

This study aimed to explain the responsibilities of a clinical supervisor in different hospital wards. There was a significant attitude towards the position of the clinical supervisor by participants of the study. The role of clinical supervisor in the medical and educational environment has been neglected. Participants also noted both the responsibilities and individual characteristics of the clinical supervisor and its role in improving the quality of education, as well as patient and medical students' satisfaction.

In this study, the category of creating motivation in learners included two subcategories of creating a supportive atmosphere and assigning tasks to learners. Determining duties and responsibilities in students makes them more motivated to perform their responsibilities. In her research, Åsa Alsiö et al. found that supervising medical students in clinical activities, as well as being clear about the expectations for each role were effective in enhancing learners' motivation (20).

Students in the clinical environment need the support and guidance of the instructors to strengthen their confidence in work, their sense of hope for the future, and to perform their professional duties properly. The main task of the clinical instructor is to provide opportunities for practical experience and to assess the status of patients. The clinical instructor should be available to answer questions and provide advice and guidance to students and friendly support the clinical supervision of students in various situations $(21,22)$. The results of Zahraei et al.'s research also showed that students' interest and motivation are influential factors in clinical education (23). In their study, Ismaili and Nazer reported that about $66 \%$ of their study participants expressed future career prospects as an effective factor in academic achievement (24).

Another category attained in the present research is to offer proper feedback to medical students. Providing feedback makes students become better aware of their performance and its improvement and promotion and try to eliminate shortcomings. Fassihi Harandi et al. in their study considered providing feedback to students during the clinical course as one of the highest acclaimed categories obtained in the quality assessment of clinical education (25).

Another category highlighted in the present research is the creation of learning opportunities among learners. The presence of an educational supervisor paves the way for the transfer of teacher experiences to the learner. The learner can easily ask the instructor about the questions and issues that he will face in the future. In a study, medical students learned skills related to dealing with the patient, clinical examinations and general procedures in the hospital. They consider the amount of learning to be dependent on factors such as motivation, patient access and quality of teaching (26).

The survey of Zamanzad et al. on satisfaction and evaluation of medical students, clerks, externs about quality of clinical education in major wards showed their low satisfaction. Lack of time management by 
instructors, roaming in the wards and wasting time were repeatedly pinpointed as causes of dissatisfaction (27).

From the attained categories, a calm and stress-free environment in students' learning was extracted. Stressful environments lead to academic problems and reduced learning. In a study, stressors during medical education on medical students have been studied. The results showed that the presence of high levels of stress and anxiety during medical education may have negative effects on students' learning and clinical success $(28,29)$.

In this study, observance of professional ethics and attention to patient rights were gleaned as the responsibilities of the clinical supervisor. Participants believed that the responsibilities of an educational supervisor are not limit to learners, but also include the patient and patients' rights. Through direct instruction, the clinical supervisor must instruct the student about patients' rights, although the positive and negative messages of medical ethics in implicitly conveyed to the learner through the hidden curricula.

Batahi and Asayesh in their study showed that more than half of medical students had moderate or poor knowledge of patient rights (30). However, in his investigation Mossadegh Rad indicated that the level of physician's awareness of patients' rights is excellent (31). As a matter of course, the high level of awareness among employed physicians compared to students can be due to their more experience in the treatment and dealing more with issues related to patients' rights. Tomlinson's study showed that clinical supervision is related to the quality and safety of patient care (13).

Regarding the theme of Personal characteristics of clinical observers, the categories of scientific competence, leading role and ethical model were obtained. Scientific competence included mastery of the professional career as well as expertise in the concepts of education. In this study, a large number of instructors had a lot of information about the concepts of teaching and learning, and their demographic information revealed that all of them had a master's degree in medical education or had taken courses related to education.

Darvishpour and Javadi-Pashak in a study entitled, "Good Clinical instructors from the perspective of nursing students extracted 6 main categories, including academic ability, clinical skills, communication skills, evaluation skills, personality, and educational management in the clinical setting (32).

In our study, two categories of "career commitment "and" social commitment "were obtained in accordance with the professional ethics model. Students observe, analyze, and evaluate professional ethics through the practical behavior and attitudes of instructors in the clinical setting and wards.

Undoubtedly, students gain knowledge through learning, directly or indirectly, by observing the behavior of professors and how to deal with the patient. To put it in another way, students repeat what the instructors do, not what they say (33). However, Torabizadeh et al. pointed out that one of the reasons for the non- 
observance of patient etiquette in medical centers is the lack of knowledge of medical staff about ethical principles and their observance in the clinic (34).

In this study, the category of "leading role" was introduced as another characteristic of the clinical supervisor. This category includes "effective communication skills", "high resilience" and "understanding managerial concepts". The clinical supervisor will need good communication with instructors, students at different levels and patients and their companions. A prerequisite for this relationship is having the ability to communicate effectively. Rahimi et al. reported communication ability and individual personality as the most important characteristic of a good instructor from the perspective of students (35).

In their review study entitled, "What makes a good clinical teacher in medicine?, Sutkin et al. reported the instructors' knowledge, technical and clinical skills of clinical reasoning, positive communication with students in a supportive environment, communication skills and passion enthusiasm as the most common themes (36).

\section{Conclusions}

In Iran, the clinical supervisor is the missing link in clinical wards and environments. Although this role is offered voluntarily by some experienced professors in clinical departments based on intrinsic motivations and love of education no special trustee has been designed for the clinical supervisor in the educational system. This has caused medical students to feel confused in their duties, responsibilities and expectations, and they have a sense of wasting time and lack of support from instructors.

Since qualitative studies seek to explain various phenomena according to the lived experiences of individuals, according to the results of this study, it seems that it is necessary to pay more attention to the role and position of the clinical supervisor in the clinical environment and to plan for better presence and training as well as effective learning in the clinical setting. It is obvious that improving the education of medical students in the clinical environment will enhance the quality of services and leads to the training of efficient and literate graduates, as well as a safe and relaxing environment. In addition, it results in a sense of safety to patients and recipients of services in the clinical environment.

One downside regarding the present study is the lack of research in the field of clinical supervision in Iran. However, the duties and position of clinical supervisor are already seen in nursing schools and good information and research have been done in this area. It is suggested to design quantitative and qualitative works in this regard.

\section{Declarations}

\section{- Ethics approval and consent to participate}

In this study, after coordination with the relevant authorities and obtaining the consent and approval of the participants, the interview was conducted. Confidentiality was also observed. This research has been 
approved by the Ethics Committee of the National Center for Strategic Research in Medical Education, Tehran, Iran (Ethical Code: 960463).

\section{- Consent for publication}

Not applicable

\section{- Availability of data and materials}

The datasets used and/or analysed during the current study are available from the corresponding author on reasonable request.

\section{- Competing interests}

The authors declare that they have no competing interests.

\section{- Funding}

This research has been done with the financial support of the National Center for Strategic Research in Medical Education, Tehran, Iran (project number 960463).

\section{- Authors' contributions}

MHK, ASGH and HRB: Study design, data analysis, interpretation of the results and manuscript drafting. SKHA, ASH and HK: Data analysis and interpretation of the results. All authors confirmed the final version for submission.

\section{- Acknowledgements}

The authors would like to express our gratitude to all those who helped us in this research and participated in the interview.

\section{References}

1. Ashoorion V, Dadgostarnia M, Esmaili A, Garakyaraghi M, Shams B, Taban H, editors. Resident as instructor of medical university clinical skills. Proceeding of first international conference of reforms and change management in medical education and sixth national medical education conference Shahid beheshti university of medical sciences, Tehran; 2003; Tehran.

2. Razavy SM, Salamati P, Shahgholi E, Honarmand M, Naderi F, Rahbarimanesh AA, et al. The Effects of Clinical Skills Learning Centers on Learning Promotion among Pediatrics Interns. Iranian Journal of Medical Education. 2011;10(4). 
3. Ahmadinezhad Z, Ziyaee V, Morvejee A. Tehran University of Medical Interns' satisfaction from the quality of clinical education by job satisfaction standard forms. Journal of Medical Education. 2002;7:8-9.

4. Sanatkhani M, Molla Z, Akbari M. Evaluation of the students' perception about clinical education and examination in Mashhad School of Dentistry (Iran) in 2009. Journal of Mashhad Dental School. 2012;36(3):211-22.

5. Sharifi B, Ghafarian Shirazi H, Momeninejad M, Saniee F, Hashemi N, Jabarnejad A, et al. A survey of the quality and quantity of clinical education from the viewpoint of medical students. Journal of Jahrom University of Medical Sciences. 2012;10(2):57-64.

6. Mardani M, Shams M, Mosadegh A, Rezapoor S. Effectiveness of training programs' clinical skills of emergency" on learning of medical students. J Lorestan Univ Med Sci. 2010;12(3):45-50.

7. Tolsgaard MG. Clinical skills training in undergraduate medical education using a student-centered approach. Dan Med J. 2013;60(8):B4690.

8. Hemati M. Khalilzadeh H. Nursing students' perspectives on effective clinical education: A qualitative study.. Iranian journal of medical education. 2012;11 (7): 718-27.

9. Goldhammer R. Clinical supervision: Special methods for the supervision of teachers: Holt McDougal; 1969.

10. Gürsoy E, Bulunuz N, Baltacı-Göktalay Ş, Bulunuz M, Kesner J, Salihoğlu U. Clinical supervision model to improve supervisory skills of cooperating teachers and university supervisors during teaching practice. HU Journal of Education, Özel sayı. 2013;1:191-203.

11. Cogan ML. Clinical supervision. Boston, 1973. Houghton Mifflin.

12. Kilminster S, Cottrell D, Grant J, Jolly B. AMEE Guide No. 27: Effective educational and clinical supervision. Medical teacher. 2007;29(1):2-19.

13. Tomlinson J. Using clinical supervision to improve the quality and safety of patient care: a response to Berwick and Francis. BMC medical education. 2015;15(1):1-8.

14. Falender CA, Shafranske EP. Clinical supervision: The state of the art. Journal of Clinical Psychology. 2014;70(11):1030-41.

15. Razmjou S, Baradaran HR, Kouhpayehzadeh J, Soltani-Arabshahi K. Comparison of quality of clinical supervision as perceived by attending physicians and residents in university teaching hospitals in Tehran. Medical journal of the Islamic Republic of Iran. 2015;29:248.

16. Delamont S. Handbook of qualitative research in education: Edward Elgar Publishing; 2012.

17. Kohlbacher F, editor The use of qualitative content analysis in case study research. Forum Qualitative Sozialforschung/Forum: Qualitative Social Research; 2006: Institut für Qualitative Forschung.

18. Graneheim UH, Lundman B. Qualitative content analysis in nursing research: concepts, procedures and measures to achieve trustworthiness. Nurse education today. 2004;24(2):105-12.

19. Lincoln YS, Guba EG. Naturalistic inquiry (vol. 75). Sage Thousand Oaks, CA; 1985. 
20. Alsiö Å, Wennström B, Landström B, Silén C. Implementing clinical education of medical students in hospital communities: experiences of healthcare professionals. International journal of medical education. 2019;10:54.

21. Newell D CR. New methods in medical education and related sciences. 1995.

22. Parsel g. Clinical teaching of new perspectives. Medical Health Development Monthly. 2000(Year 3 Number 256).

23. Hassan Zahraei R, Atashsokhan, G, Salehi, Sh.. Comparison of factors associated with effective clinical teaching Instructors and Students. Iranican Jornal of medical education. 2008;7(2):1-8.

24. Esmaili $\mathrm{H}$, Nazer M, editors. Effective factors in Rafsanjan students training base on them viewpoint. 8th National Congress of Medical Education; 2009.

25. Fasihi HT, Soltani AS, Tahami S, Mohammad AS. Viewpoints of medical students about the quality of clinical education. 2004.

26. Khodabande M. Reviews clinical faculty, residents, interns, and graduate medical about the quality of clinical education Semnan University of. Medical Sciences: PhD thesis of Medicine, University of Medical Sciences, Semnan University; 2002.

27. Zamanzad B, Moezi, M, Shirzad, H,. Survey of Satisfaction and evaluation of medical students, clerks, externs about quality of clinical education at the University of medical sciences Sharkord. Journal of Semnam University of Medical science. 2007;9(1):13-21.

28. Khan MS, Mahmood S, Badshah A, Ali SU, Jamal Y. Prevalence of depression, anxiety and their associated factors among medical students in Karachi, Pakistan. Journal-Pakistan Medical Association. 2006;56(12):583.

29. Sarikaya O, Civaner M, Kalaca S. The anxieties of medical students related to clinical training. International Journal of Clinical Practice. 2006;60(11):1414-8.

30. Bathaei SA, Asayesh H. Medical students' awareness of patients' rights in Qom university of medical sciences and health services (2010). Iranian Journal of Medical Education. 2012;12(5):347-55.

31. Mosadegh Rad A. Investigating the relationship between patient's awareness on patient right and their satisfaction of hospital services. Teb va Tazkiyeh. 2005;14(58):16-24.

32. Darvishpour A, Javadi-Pashaki N. Good Clinical Instructor from the Perspective of Nursing Students: A Qualitative Study. Journal of Qualitative Research in Health Sciences. 2019;7(4):372-82.

33. Yamani N, Liaghatdar MJ, Changiz T, Adibi P. How do medical students learn professionalism during clinical education? a qualitative study of faculty members' and interns' experiences. Iranian Journal of Medical Education. 2010;9(4):382-95.

34. Torabizadeh C, Ebrahimi H, Mohamadi E. The relationship between patients' privacy and dignity. BMC Med Ethics. 2012;6:119-32.

35. Rahimi A, Ahmadi F. The obstacles and improving strategies of clinical education from the viewpoints of clinical instructors in Tehran's Nursing Schools. Iranian journal of medical education. 2005;5(2):73-80. 
36. Sutkin G, Wagner E, Harris I, Schiffer R. What makes a good clinical teacher in medicine? A review of the literature. Academic Medicine. 2008;83(5):452-66. 